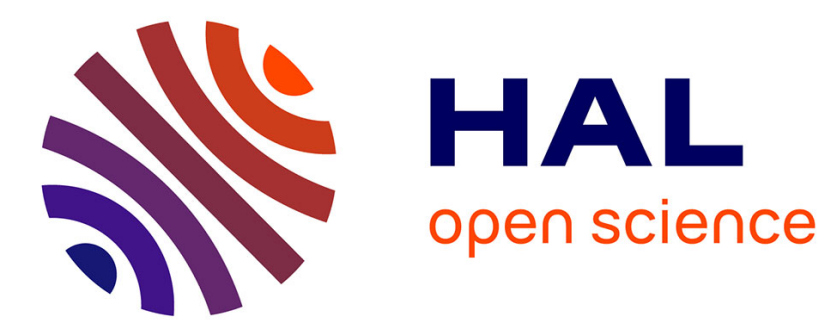

\title{
Do open online projects create social norms?
}

Godefroy Dang Nguyen, Sylvain Dejean, Nicolas Jullien

\section{To cite this version:}

Godefroy Dang Nguyen, Sylvain Dejean, Nicolas Jullien. Do open online projects create social norms?. Journal of Institutional Economics, 2018, 10.1017/S1744137417000182 . hal-01547505

\section{HAL Id: hal-01547505 \\ https://hal.science/hal-01547505}

Submitted on 26 Jun 2017

HAL is a multi-disciplinary open access archive for the deposit and dissemination of scientific research documents, whether they are published or not. The documents may come from teaching and research institutions in France or abroad, or from public or private research centers.
L'archive ouverte pluridisciplinaire HAL, est destinée au dépôt et à la diffusion de documents scientifiques de niveau recherche, publiés ou non, émanant des établissements d'enseignement et de recherche français ou étrangers, des laboratoires publics ou privés. 


\title{
Do Open Online Projects Create Social Norms?
}

\section{Godefroy Dang Nguyen ${ }^{1}$, Sylvain Dejean², Nicolas Jullien'}

\author{
1: IMT Atlantique-UBL, M@rsouin-LEGO (FirstName.name@imt- \\ atlantique.fr) \\ 2: Université de la Rochelle, Sylvain.Dejean@univ-Ir.fr
}

\begin{abstract}
While most scholars emphasize the role of pro-social motivations of contributors in building open online communities, we show that mere users also adhere to their norms. For this, we have designed an original experimentation protocol. With the help of the French Wikimédia Foundation, we have questioned a large sample $(\mathrm{n}=13000)$ of Wikipedia users (contributors or not). They have been invited, after having expressed their feelings about Wikipédia, to play a Dictator Game. A large proportion of respondents, in particular the simple users, chose the equal split (66\% of the sample). This suggests that they have adhered to a social norm of sharing. Investigating the determinants of this result, we prove that an involvement measured by usages (intensity and variety), as well as attachment to, and time spent on Wikipedia, are correlated with the choice of the 50/50 split in the DG. Even more, the method of instrumental variables gives an indication that the adherence to the social norm of sharing may be endogenously determined by the involvement in the open online community. Our result thus highlights the importance of interactions with the institutional and technical framework of the community, to abide by a norm of sharing, in particular for those who seem to play a very passive role in Wikipedia project, the mere users.
\end{abstract}

JEL classification: L17, L86, H41, C86

Keywords: social norm, dictator game, 50/50, online epistemic community, Wikipedia

\section{Introduction}

Open online volunteer projects, which mobilize hundreds (Linux) to thousands of contributors (Wikipedia, P2P platforms) are alive and well, impacting several industries and raising many issues concerning collective behavior in the digital age. However, the Pareto distribution of contributions - meaning that the provision of the public good depends on few people - has always been considered as a strong limitation to the development of these communities.

This leads to two consequences. First, the development and management of online projects is strongly influenced by the perception of the central role of contributors. Recruiting and facilitating those who are the most able to contribute, and ignoring the "simple" users often considered as free riders ${ }^{1}$, becomes a priority. Hence, and this is the second consequence, there is a large body of literature dedicated to understanding the motivations of these contributors.

Consequently, the understanding of both the contributors' and users' motivations as well as the building of incentive schemes, relies on a significant underestimation of the importance of interactions, inside the community and with its institutional and technical framework. Contributions to, but also the intense use of such collective knowledge goods, may create a personal feeling of social involvement, such as an attachment to the project and / or to the 
community. If this is true, social motivations endogenously created by the community, may contribute to explain the survival of the project. This hypothesis makes sense in the context of open online communities, where success depends on the ability of the platform to provide collective rules, codes, in a word norms, to foster costly effort by involved members (such as content production or even intense use) (Butler et al., 2007; Safner, 2016). The hypothesis makes also sense, whenever the project leaders want to prevent the users from switching to alternative offers, possibly better in terms of quality, or simply more adapted to their needs (Linux vs Windows), or to have them donate to maintain the free access to the platform (Wikipedia). In other words, the capacity of collective projects to trigger an implicit feeling of belonging within the whole community and not only among contributors, may be a key factor for sustainable success.

However, while Safner (2016), described, in the case of Wikipedia, the importance of the rules and norms to govern the cooperative provision of the common resource, nobody, to our best knowledge, has investigated the adherence to such cooperative norms within the whole group of users of Wikipedia or any other online community. This article instead, evidences the capacity of an online project to generate cooperative behaviors beyond the contributors. For this, we took advantage of a response to an experimental game (the dictator game, or DG) played by a large number of Wikipedia users and contributors $(n=13000)$. The main result of the game was that the equal split (50/50) was chosen by an overwhelmingly large part of our sample (66\%), and we have found no difference between contributors and simple (but committed) users of the online encyclopedia. This twofold result - a majority deciding on the equal split and no difference between contributors and committed users - first challenges the existing literature which suggests that cooperative motivations are correlated with voluntary contributions. It also shows that usage, attachment and time spent on Wikipedia are linked to the choice of what can be seen as a social norm, sharing with the 50/50 rule. We suggest that this attitude is probably the outcome of participation and involvement in the community: the more people are involved, the more they choose the social norm of equal split in the DG, because they have learned that sharing is acknowledged in the Wikipedia context, and should be the expected behavior. In other words, they may have learned the norm.

The article is organized as follows: in section 2 we first review the literature regarding motivation, identity, and norms, and then the articles dealing with the dictator game as an indicator of the respect of a norm. In section 3 we present our method, an experiment on Wikipedia readers and contributors. In section 4 we run some econometric tests to assess the determinants of the equal split. We discuss in section 5 the consequences of the results of the tests, their limits and direction for future research, before concluding.

\section{What are Social Norms designed for?}

Departing from the standard model of a rational and selfish individual, one strand of economic literature has, in connection with social and evolutionary biologists, suggested that prosocial behaviors have evolved to sustain cooperation, a key feature of the survival of the human species (Gächter, 2014; Gintis et al., 2003; Seabright, 2012). Established in long term relationships, these cooperative behaviors often become norms.

Young (2015)d described the different mechanisms that support the existence of norms, including the need for coordination and the use of a focal point as a process to make decisions appear to be central, as discussed in the coordination games literature (Schelling, 1960; Sugden, 1995). Those norms may emerge very quickly. Social pressure also supports the development of normative behavior. As a consequence, non-compliance causes dissatisfaction, such as guilt, shame, embarrassment or anxiety, and conversely compliance with a norm can produce satisfaction and pride (Elster, 1989).

Another mechanism proposed by Young (2015) to explain the impact of norms, is signaling and symbolism, and relies on what Akerlof and Kranton (2000) called 'identity'. According to this vision, a norm signals membership in a particular group or community which prescribes specific attitudes. According to Bicchieri (2002), identity tends to favor norms which characterize the group as such and distinguish its members from others. Instead, social norms 
may have a broader scope, and apply to a large part of the population, beyond the group (fairness is an example). In a nutshell, and as Young (2015) claimed, norms are the unwritten codes and informal understandings that define what we expect of other people and what they expect of us. And those codes facilitate the functioning of projects, because, as pointed out by Commons (1931), they define what "the individual can, cannot, must, must not, may or may not do" in this context.

\subsection{The Role of Norm and Identity in Open Online Communities}

Norms and identity have an impact on users' participation in online communities. Zhou (2011) showed that both social identity and group norms (i.e. norms and values shared inside a group) have a positive impact on user participation, while subjective norms (i.e. the effect of other's opinion on a particular behavior) have not.

Using a public good game, Bicchieri (2002), in a study of the impact of communication on cooperative behavior in an online community, showed that allowing communication dramatically increases cooperation. In a discussion whether communication elicits identity or social norms, Bicchieri (2002) argued for the latter.

This echoes the work of Greenstein et al. (2016) in the case of Wikipedia and its contributors: on controversial topics, people tend to contribute to articles which reflect their own opinion (for instance, a Republican contributing to articles which describe ideas favored by Republicans) - a behavior grounded on identity -, but, in the long run, the discussion among contributors to such articles becomes more and more neutral (one of the Wikipedia's five pillars) - rules and social norms emerge through interactions-. In fact, it is as if the norm of neutrality emphasized by the Wikipedia charter has emerged not from a deliberate decision of contributors intending to abide by the Charter rules, but spontaneously from multiple social interactions among contributors, mediated by the social control of the rule enforcers, the administrators of Wikipedia, who are allowed to exclude from contributing those people who sabotage this process.

In that perspective Safner (2016), using the framework from Hess and Ostrom (2006), explained how cooperation between contributors is enforced in Wikipedia by its rules of publication (the "five pillars" ${ }^{2}$ ), but also by its socio-technical organization (the Wikimedia software platform), and by the social interaction as well as the administrators acting as policy makers, to use the phrasing of Hess and Ostrom (ibid).

But mere users (non contributors) by definition do not interact directly. Hence, if users, in certain circumstances, behave pro-socially, this cannot be due to interaction, but instead to one of the two mechanisms described by Bicchieri (2002): either a common compliance to a social norm, namely a collective behavior enforced by the anticipation of the persons who follow it that others will do the same, or to a feeling of attachment to this project and its identity. Many experimental games help to reveal such attitudes and decide between them. In the context of our research, we relied on the Dictator Game (DG) as a means to hint (or not) at the existence of social norms of cooperative behavior among contributors and, possibly, users.

\subsection{The Dictator Game to Detect the Existence of a Norm}

The dictator game implies that a first player, 'the dictator', decides to split an initial endowment between him- or herself and a second player. The second player does not make any decision, so the choice of the first player to give a non-zero amount to the second player is a non homo-economicus-rational choice. Any deviation from 0 can be considered as the manifestation of a form of prosocial behavior.

The claim that the Dictator Game is sensitive to the context has been debated. A consensus has emerged that the design of the game (changing the distribution of offers) has a strong effect on giving (Bardsley, 2008; List, 2007), as well as the worthiness of the recipient (Eckel and Grossman, 1996), or the social distance between players (Hoffman et al., 1996). For instance, cultural differences can be considered as an expression of different social norms. 
Henrich et al. (2010) showed that in a sample of 15 small-scale societies, norms and institutions played a role in how fairness was perceived. Related findings appear in the metaanalysis of Tisserand et al. (2015) : the amount given by individuals in the DG varied across countries, and industrialized countries were less generous.

These results provide support for considering a - statistically significant - variation from zero in giving in the DG within the group as an indicator of the influence/ strength of a norm, explained by the context.

But the DG may lead to any outcome besides the 0 choice. Hence, any aggregation on a particular value also reveals a possible latent norm. One of the contenders, is the 50/50 split, which has a special role for the literature. Andreoni and Bernheim (2009), pointed out the importance of the equal split in different economic contexts, and emphasized its social nature. They showed that the wish to be perceived as fair by peers explained the choice of the equal split in the DG. Both Krupka and Weber (2013) and Eckel et al. (2011) exhibited a prevalence of this norm in student populations: the former showed that the 50/50 split in the DG is perceived as 'socially appropriate', while according to the latter, the equal split was valued by students, especially those who scored highly on a social competency scale and who were more sensitive to social pressure. Ensminger (2004) showed how access to the market (labor/ trade) in East Africa was associated with giving half of the endowment in the DG. In experimental designs of the DG too, the 50/50 split generally often emerges as one of the modes in the distribution of givings.

Young $(2015,1998)$ has suggested an evolutionary basis for the emergence and persistence of the 50/50 split, proving that it is an equilibrium in a game with self-reinforcing behavior. The development of such a particular norm may be seen as a coordination problem. In line with Henrich et al. (2010), this result suggests that the need for coordination among unrelated individuals promotes the emergence of the 50/50 norm. This theoretical framework seems appropriate in the particular case of online communities, where people interact virtually, some of them anonymously, and in a very decentralized manner.

But in the context of a pure DG there is no strategic interaction and therefore choosing the 50/50 split does not respond to any strategic need for coordination. However, people may have been accustomed, in previous coordination issues, to adopt such an attitude, which could have become a kind of reflex. Cognitive psychology has long recognized the existence of cognitive reference points (see for example, Rosch, 1975).

In fact, in the context of online projects, or "commons", there are a lot of coordination problems among contributors, triggered by the associated editing costs - a task bringing no immediate reward to the editor. For example, who begins? In what order do editors intervene? It may be that a coordination process is set up among the editors, which becomes a focal point for editing tasks of subsequent contents. Hence, contributors may have been familiar with focal points and decide that the 50/50 split in the DG is a point which reflects what they do in practice, as contributors to an online project. Hence, if an overwhelming choice of the 50/50 split is due to a focal point, considered as a process to solve coordination problems (Schelling, 1960; Sugden, 1995), this behavior will be particularly present within the contributors community.

If it is signal of a more general norm of reciprocity (Andreoni and Bernheim, 2009), or guilt aversion (Battigalli and Dufwenberg, 2007), or inequality aversion, due, for instance, to the political philosophy of the project, this may spread to the whole population (even if, as mentioned, the 'community belonging' feeling, is firstly felt by the contributors), and may be more dependent on the level of use, or of the importance of the project for the respondent.

We have been able to test these two rival explanations in the context of one particular 'commons', Wikipedia.

\section{Method}

With a community of around 700,000 registered contributors (for the English language version) and more than 480 million visitors each month ${ }^{3}$, Wikipedia provides a particularly 
fertile field for experimentation. With the help of the French Wikimédia Foundation, in February 2015 we put a banner on the homepage of the French-language Wikipédia ${ }^{4}$. This banner advertised for a questionnaire that asked both contributors and users how they interacted with Wikipedia, whether they contributed (if so how) or not, and how much they value the "Free Encyclopedia". To test the prosocial attitudes of respondents in general, we invited them to participate in a Dictator Game (DG). The game is standard in the experimental literature of social science, it is easy to implement, not subject to misunderstanding biases and does not involve strategic interaction. Here it was conducted on a very large scale, as over 13,000 people completed the questionnaire. This huge sample enabled statistically relevant conclusions to be drawn on how and why people behave in a large prosocial context.

Adopting a kin methodology, Algan et al. (2013) interviewed significant contributors to Wikipedia through a questionnaire and had them play four experimental games (the trust game, the dictator game, the ultimatum game and the public good game) in order to reveal their motivations. They showed that reciprocity as well as the preference for social image (reputation) played a strong role in explaining the volume of contributions by registered contributors and even more by the so-called "administrators" 5 .

Likewise, when Wikipedia was blocked in mainland China, Zhang and Zhu (2011), took the opportunity to examine the contributions of non-blocked contributors (living in Taiwan, Singapore or overseas). They established that these groups reduced their contributions during and after blocking. Their explanation was that contributors perceived that they received fewer social benefits from their work.

Neither of these previous studies tried to evaluate the strength of the social norm of reciprocity beyond the contributors, to see if those contributors are more pro-social than the users of Wikipedia, for instance.

\subsection{Data Collection}

Once the survey had been completed, respondents were invited to play a game to win a voucher. The game was a standard version of the Dictator Game (DG): users were asked to split $€ 10$ between them and another person "who was assumed to have completed the survey". After the respondents chose the amount they wanted to keep, a dialog box informed them of the amount they kept and their 'gift' to the other person. This step was designed to help them to understand the protocol. As we were unable to systematically pay the amounts earned by the (numerous) participants, 100 were randomly selected to win a voucher for an amount equal to the double of the amount won in the DG. Respondents were informed on the draw and the number of vouchers available, but were unable to estimate the probability of being picked, as they did not know the number of people who had completed the questionnaire.

Almost 30,000 Wikipédia users started the survey and 16,879 finished it. Among those who completed it, 13,672 played the DG. In the remainder of this article and in our analyses, we only considered those 13,672 respondents who completed the survey and played the DG. This data collection method allowed us to construct a non-probability-based sample of French Wikipédia users (and contributors).

\subsection{An Experiment which Induces Cooperation.}

To the best of our knowledge, only a few papers have reported results based on such a large DG experiment, especially in the context of an open online community. The drawback of this massive participation was our inability to control for the impact of the survey on the choice of the respondent. First of all, these choices may have been simply random, as the incentive to think before answering was low (as was the reward). Despite this, their distribution is not

\footnotetext{
4 When speaking of Wikipedia in general, we use the term 'Wikipedia'. When speaking of the French language project, which was the point of entry for the survey, we use the French term, Wikipédia.

5 "Administrators" in the Wikipedia jargon are those who are entitled to intervene in the discussion among contributors, to ban "vandals" and close their account, etc. They are elected by the community among the largest

contributors who volunteer.
} 
uniform, but very much centered on the 50/50 split (Figure 1a), both decisions to give 0 or 10 are also local maxima and could also represent focal points. Note that the same local maxima appear in Engel's histogram (Figure 1b). The latter is the (constructed) addition of on 328 treatments of DGs, representing more than 20,000 observations, extracted from the experimental economics literature, and can be considered as a general picture of giving behavior in the DG. The relative importance of the local maximum in both cases is different. In Engel's, the highest is the selfish solution (giving 0), while this is only the third maximum in our own histogram.

Figure 1: Comparison of the distribution of individual giving among Wikipédia users and in the metaanalysis by Engel, (2011)

(a) Distribution of individual giving among Wikipédia users ( $\mathrm{N}=13528)$

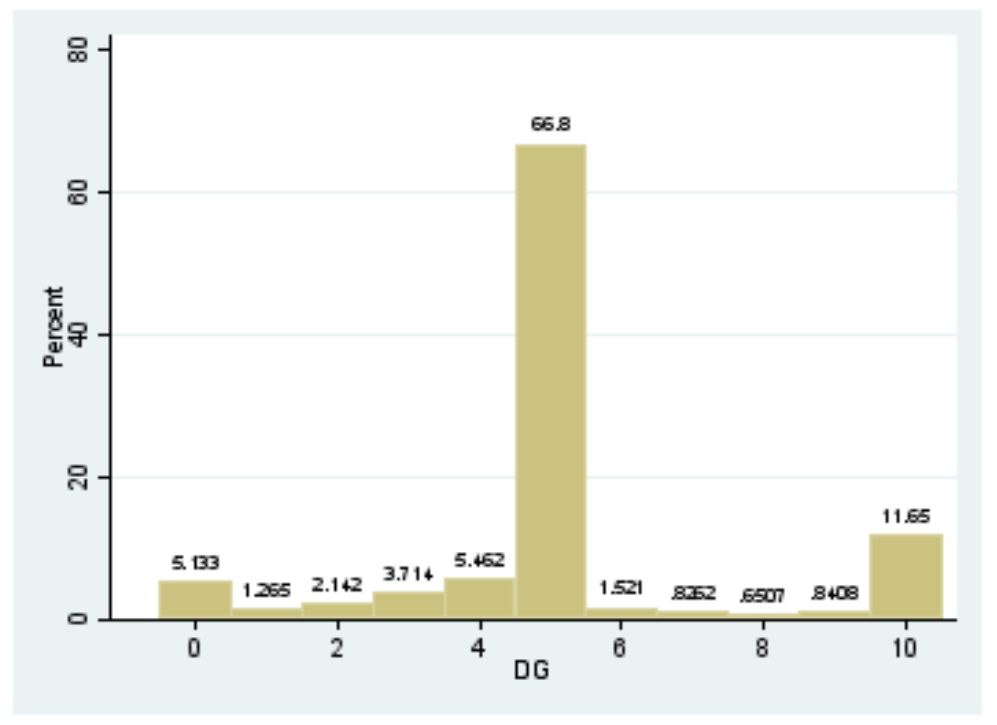

(b) Distribution of individual giving in the meta-analysis by (Engel, 2011)

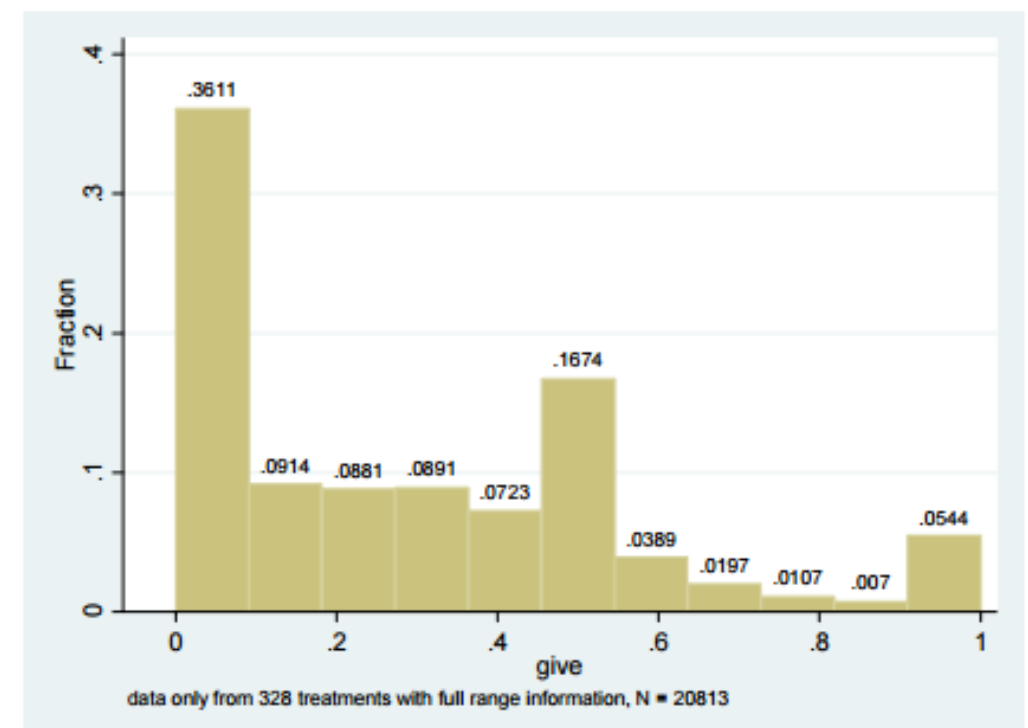

We can confidently claim that the answers were not random. Actually, they were, to some extent, forced by our experimental design toward cooperative answers, and possibly the 50/50 split. The Wikipédia users we surveyed, volunteered to spend 20 minutes to complete a questionnaire, and subsequently were asked to share the gains with a 'fellow participant', who completed the questionnaire too. This may have triggered a cooperative attitude, inducing them to elicit the 50/50 split, because, in addition to the 'identity' explanation we wanted to 
test, which was the goal of this requirement, another obvious explanation is given by Eckel et al. (1996), who reported an increase in giving when the recipient 'deserved' it. This result is confirmed by Carpenter and Myers (2010), who asked a sample of voluntary firefighters to play a modified version of the DG. Following Eckel and Grossman (1996), they asked participants to share an initial sum with a charity of their choice. In this context, the mode was to give the whole amount to the charity.

\subsection{The Variables}

Table 1 describes all the variables.

\subsubsection{The Dependent Variable}

As the DG result represented various social motivations, and in order to identify the specific characteristics of the 50/50 norm as a social norm, we estimated, in addition to the equal split, the likelihood of giving 0 (selfish behavior) and 10 (altruistic behavior).

\subsubsection{The Explanatory Variables. Measuring the Involvement in the Online Project}

Respondents were asked whether they had ever contributed to Wikipedia, and if so, how often. This led to three levels of contributions: Contrib3 were regular contributors (as defined in Dejean and Jullien, 2015)), Contrib2 for those who contributed occasionally only; while Non-contributors (Contrib1) provided the reference point.

We considered three additional measures of Wikipedia patronage. The first was an indicator of Wikipedia usage intensity. We asked respondents about their level/ intensity of use with regards to three types of usage, based on a scale of "never", "rarely", "sometimes" or "often". The questions asked were: "In the context of your personal activities (talking with friends, hobbies, etc.) do you use Wikipedia to: 1) Check information 2) Look for a definition 3) Discover new things and deepen your knowledge”. For each of these answers and for each of the three levels of intensity, we designed a variable. Check_info3 (resp. Look_def3 and Deep_know3) is equal to one if the respondent used Wikipedia to check information often (resp. Look for a definition, and Deepen knowledge), Check_info2 (Resp. Look_def2 and Deep_know2) if she did it sometimes or rarely, and Check_info1 (Resp. Look_def1 and Deep_know1) if she never did it. Finally, as these three different usages could have been correlated, we aggregated the results in a score variable that is a proxy for the intensity of usage. WikiUse is a quasi-continuous variable ranging from 3 to 12, where 3 represent no use, and 12 a very intensive use.

The second measure of the support to Wikipedia is the variable WikiPref, which is a proxy for an attachment to Wikipedia. The question was: "If Wikipedia disappeared, would it be: 1) A disaster 2) A significant loss 3) Somewhat harmful 4) A 'non-event' (no impact) 5) A good thing”. Wikipref 3 indicated that the disappearance of Wikipedia would be a disaster (34\% of our sample); Wikipref2 indicated that it would be a considerable loss (55\%); Wikipref1 indicated that it would be somewhat harmful, a non-event or a good thing (11\%).

The third variable for measuring support, is the number of years participants have been using Wikipedia (WikiTime), which is considered as a measure of the (possible) impact of the progressive integration of the norm of prosocial behavior of the community, and the development of a feeling of belonging to this community. WikiTime is a continuous variable ranging from 1 to 5, increasing with seniority. The question was: "For how long have you used Wikipedia? 1) Less than a year 2) Between 2 and 4 years 3) Between 5 and 8 years 4) Between 9 and 12 years 5) More than 12 years”. 


\subsubsection{The Control Variables}

We also considered other potential determinants of an equal split, notably the usual sociodemographic characteristics (see Table 1 for further details).

Our survey also provided information to test the robustness of the relationship between the 50/50 choice and the involvement in Wikipedia.

The respondents were asked whether they used Wikipedia for professional or personal purposes, with the hypothesis that if the use of Wikipedia was professional, people would be less committed to the project, and less influenced by its social message. This to test the hypothesis that in 'professional' situations (student work or employment), the information looked at may be of less personal interest, hence the source may be of less importance. The variable WikiUse_Pro which mirrors WikiUse, is introduced as an estimate in Table 5.

As described in the literature review, social norms can have a cultural origin. This explains why the giving behaviors seen in the DG differ according to the players' country of origin (Tisserand et al., 2015). As our survey was promoted on the homepage of the French-language Wikipédia, all respondents were French speakers. It is thus possible that the equal split norm is driven (at least partially) by shared values or culture or identity signal associated with the French language. To control for this potential in-group bias, we exploited the fact that not all the respondents lived in France in order to create the variable French which takes the value of one if the respondent live in France, 0 otherwise (23\% lived abroad: 5\% in Belgium, 6\% in Canada, 3\% in Switzerland, 1\% in Africa, etc.)

Finally we asked the respondents whether they believed that "some of those who edit articles in Wikipedia are paid to do it". This assumed that this belief could be an impediment to the norm of sharing elicited in the DG. The variable Edit_paid equals one if the respondent thought that some article writers were paid to do so and 0 otherwise.

\section{The results}

\subsection{Patronage of Wikipedia Induces the 50/50 split, Contribution Does Not}

The main result is that commitment to Wikipedia is associated with equal giving. Both the intensity of use and an affirmed attachment to the platform are associated with an increase in the likelihood of choosing the equal split. This result holds for all variables shown in Table 2 . On the other hand, Table 3 shows that when the model contains all the variables associated with the involvement in Wikipedia, some of them cease to be significant. For instance, years of experience with Wikipedia is only associated with an equal split when this is the only independent variable. This means that this variable is probably colinear with covariates (e.g. with age), and other measures of patronage (WikiPref, WikiUse). In fact, both the level of attachment and the propensity to use in different contexts, are likely to increase with time spent on the platform. The same remark applies to the different usages in Wikipedia, as only the motive of checking a piece of information (and less significantly deepening knowledge) can be associated with the choice of the equal split. The collinearity between these different usages can explain why they provide redundant information. Controlling for the potential redundancy of information by considering these usages additively with the WikiUse variable, leaves the latter significantly associated with the equal split in Tables 2.

The fact that contributions are not associated with the equal split is more surprising, as contributors seem to be more committed than the other "simple " users. This result leads us to admit that social motivations go beyond the act of contributing (contributors only represent $1 \%$ of the users), engaging all the participants, making them adhere to the project of cooperative production (a social norm), and/or building a feeling of belonging to a community (identity).

However, the most striking result is that none of the variables used to proxy attachment and patronage of Wikipedia is linked to altruistic behavior (giving $€ 10$ and keeping 0), some of them are even negatively associated with it (see Table 3). Less surprisingly, attachment to, and patronage of Wikipedia, are not even linked with the selfish behavior (giving $€ 0$, keeping all). 
All in all, the equal split is the only choice associated with an involvement in Wikipedia. The singularity of the fifty-fifty sharing choice reinforces our belief that social norms go some way to explaining prosocial motivation in open online communities.

Beyond prosocial attitudes, regression coefficients associated with socio-demographic characteristics (see Table 4) are in line with the DG literature. Older and retired respondents are more altruistic (they are more prone to give $€ 10$ ). Students and educated respondents are associated with more opportunistic behavior. All other things being equal, the likelihood of choosing the 50/50 split in the DG increases for females and users aged between 20 and 50 . This result differs from Eckel et al. (2011), who found that the 50/50 norm is common among students (high school and university), and that there was no gender difference. However, it should be noted that in their study, students were playing against each other, and conformity with the reference group or "identity" may have played a stronger role than in our study.

Relying on the benchmark regressions in Table 3 we could derive marginal effects from these estimates. All things being equal, considering that the disappearance of Wikipedia would be a "disaster" or a "major loss" increases the probability of choosing the equal split by respectively 7.8 and $7.4 \%$. Checking information often leads to a $4.3 \%$ increase in the choice of the equal split. Scoring the highest value for the variable intensity of usage (WikiUse) leads to a $7 \%$ difference in the choice of the 50/50, as compared with the lowest scoring for this variable. Combining a high score in WikiUse and a strong attachment to Wikipedia leads to a $15 \%$ increase in the probability of choosing the equal split.

The socio-demographic variables which have the largest impact are gender and age. Being a female can be associated with a $6.1 \%$ increase in the choice of the equal split and under 50 years old leads to an increase of $10.5 \%$.

To highlight the difference between those who are strongly involved in the community and those who are not, we could compute marginal effects for different values of the independent variables. For instance being a female under 30 years old and an intensive user of Wikipedia (WikiUse =12) who considers that the disappearance of Wikipedia would be a "disaster" increases the probability of choosing the equal split by 33\%, as compared with a male over 30 years old, not involved in the community (WikiUse $=3$ and Wiki_pref1=0).

Table 5 estimates the benchmark model (i.e. Column 1 in Table3) with additional controls for the choice of the equal split.

While a personal motive is associated with an increase in the propensity to choose the equal split in the DG, this is not the case for professional usage (see Columns 1 and 4 in Table 5).

Columns 3 and 4 of the same Table 5 show the result of estimates that take the cultural variable into account. As expected, living in the same country increases the propensity to choose the same social norm. However this does not alter the previous result concerning the relationship between involvement in Wikipedia and the equal split choice, which remains equally strong. Fewer people living outside France have chosen the 50/50 split as they felt less committed to the French cultural community.

As expected, the belief that some wikipedians are paid to edit articles is negatively correlated with the propensity to choose the equal split. It seems obvious that a social norm based on sharing behavior is prevented from growing whenever some anticipate that others are motivated by extrinsic financial motivations. More than just being a control variable, Edit_paid can also be considered as an indirect test of the existence of the norm, since not being paid for providing knowledge in Wikipedia is an important institutional framework in the community. Thus it is a rule which enables to create or strengthen the norm elicited in the DG.

All these tests reinforce the conclusion that the 50/50 split is a contextual, Wikipediadependent behavior.

\subsection{The Project Has Created the Norm}

The question of whether the preference for equal sharing pre-existed in the personality of Wikipédia users, or whether it is the support to the commons (Wikipedia), which has fostered the equal split norm, can be addressed using an instrumental variable (IV) methodology.

We considered endogenous variables related to the use of, and attachment to, Wikipedia in the 
following system of equations:

$$
\begin{gathered}
\text { equalsplit }=\alpha_{1}+\beta_{1} X_{1}+\sigma_{1} \text { Wiki }_{\text {use }}+\varepsilon_{1} \\
\text { Wiki }_{\text {use }}=\alpha_{2}+\beta_{2} X_{2}+\varepsilon 2
\end{gathered}
$$

where $\mathrm{X}_{1}$ is the vector of socio-demographic explanatory variables described in Table $1 . \mathrm{X}_{2}$ contains all the variables in $\mathrm{X}_{1}$ plus the instrument.

Smartwiki is the instrument. This variable takes the value of one if the respondent consults Wikipédia using a smartphone. To be consistent, the instrument should satisfy both the inclusion and exclusion conditions. Concerning the condition of inclusion, Smartwiki should be a natural regressor of the endogenous variables (preference and usage intensity). The instrument should also be correlated enough to induce large variation of the endogenous variable, since a "weak instrument" (Bound et al., 1995) can lead to significant inconsistencies in the estimate. To ensure that the instrument brings sufficient information, a common rule of thumb is to have a value larger than 10 of the F-statistic against the null hypothesis that the instrument is irrelevant, in the reduced form model. This is the case for all the potential endogenous variables tested in Table 6 (see the F-stat at the bottom of the table). As $\varepsilon_{1}$ is unobservable we were unable to test the independence between the instrument and the main variable of interest. However, we assumed that consulting Wikipedia from a smartphone should not have a direct impact on the decision to make a 50/50 split in the DG. Would it be the case, this would happen via the increase in the intensity of usage or preference for Wikipedia, satisfying the specification above.

The assumption made to justify the exclusion condition is that using a smartphone to read Wikipedia does not help to build the norm. The mobile version of Wikipedia, even if largely responsive, does not provide additional features as compared with desktop version. As reading is the main usage of Wikipedia, using a smartphone for this experience is probably convenient but the reading experience is downgraded and the use of a smartphone is clearly not suitable for deep research or for contributing or interacting with others. For these reasons it seems that the very fact of using a smartphone and the mobile version of Wikipedia, cannot be considered as a feature or a service that helps to comply with a norm, beyond the fact that it helps to increase the intensity of use in particular conditions (i.e. mobility).

Table 6 shows the results of the estimation of the likelihood of choosing the equal split in the DG taking the instrumental variable and considering respectively Wikiuse, Wikipref ${ }^{6}$, and Wikitime as endogenous variables. The results confirm those in Table 2. Introducing an instrumental variable cannot prove the existence of a causality. However, still under the assumption that the instrument is valid, we cannot invalidate the existence of a causal impact on the equal split, of the involvement in the community.

This result goes beyond the correlation between cooperative behavior and involvement in the open online project and provides the first piece of evidence that prosocial motivations are not only inherent to individual preferences but can also be built inside the community.

\section{Discussion}

This paper has shown that involvement in an open online community is associated with the adherence to sharing behavior, revealed by the choice of an equal split in the DG. Long-term users who declare a strong attachment to Wikipedia are more likely to choose the 50/50 split in the DG. Interestingly, those who contribute to the open online project are not more willing to adhere to the social norm, suggesting that this kind of prosocial motivation is not limited to contributors. Finally, the method of instrumental variables has been used to sustain the existence of a causal relationship between the commitment with the online project and the choice of the equal split.

The mechanisms behind this choice: norms, identity generated by the project or by a self- 
selection by the project users, has to be discussed.

As shown in Section 2.3, both the existence of a norm of reciprocity, and the result of a coordination game, are two competing assumptions to explain the 50/50 choice in the DG. The fact that the social norm is shared by the non contributors means that the majority of users who adhere to this norm are not involved in a coordination process. The existence of a norm of reciprocity is thus a more plausible explanation. This motivation was highlighted in the work of Algan et al. (2013), but only among contributors. Our result calls for the consideration of reciprocity in an extended context that includes both contributors and users. The formers give their time and knowledge to write and discuss articles that readers read, while readers give their attention and provide an audience. Both are a necessary part of the community. Both contribution and attention formed the foundation for the social benefits described by Zhang and Zhu, (2011). This highlights the importance of non-contributors in the dynamics that leads to the provision of knowledge in the context of Wikipedia.

This result minimizes the role of social interaction as the mechanism explaining the emergence of a cooperative behavior. If so, the contributors should be more prone to share this behavior, as they are more in contact with the others (peer appraisal is important to them) and with the project's policy makers.

Another explanation may be that being involved in Wikipedia either as a contributor or a committed user, provides a feeling of belonging and a signal of membership, in the spirit of Akerlof and Kranton (2000). This feeling, or 'identity', may lead to the consideration of others as peers. It may thus be natural to share half of a gift with a peer when possible. This attitude is reinforced by the fact that the community is large and anonymous, and there is no way to identify individuals or to personally tailor a gift. Users have in common their attachment to Wikipédia which makes them worthy of receiving half of the pie. But this also gives them the opportunity, as donors in the DG, to signal their worthiness to their peers, as the financial incentives of the DG was low (so was the cost of signaling this identity).

Figure 2: Share of users who chose the equal split according to their answer to questions about their proximity with the project's philosophy

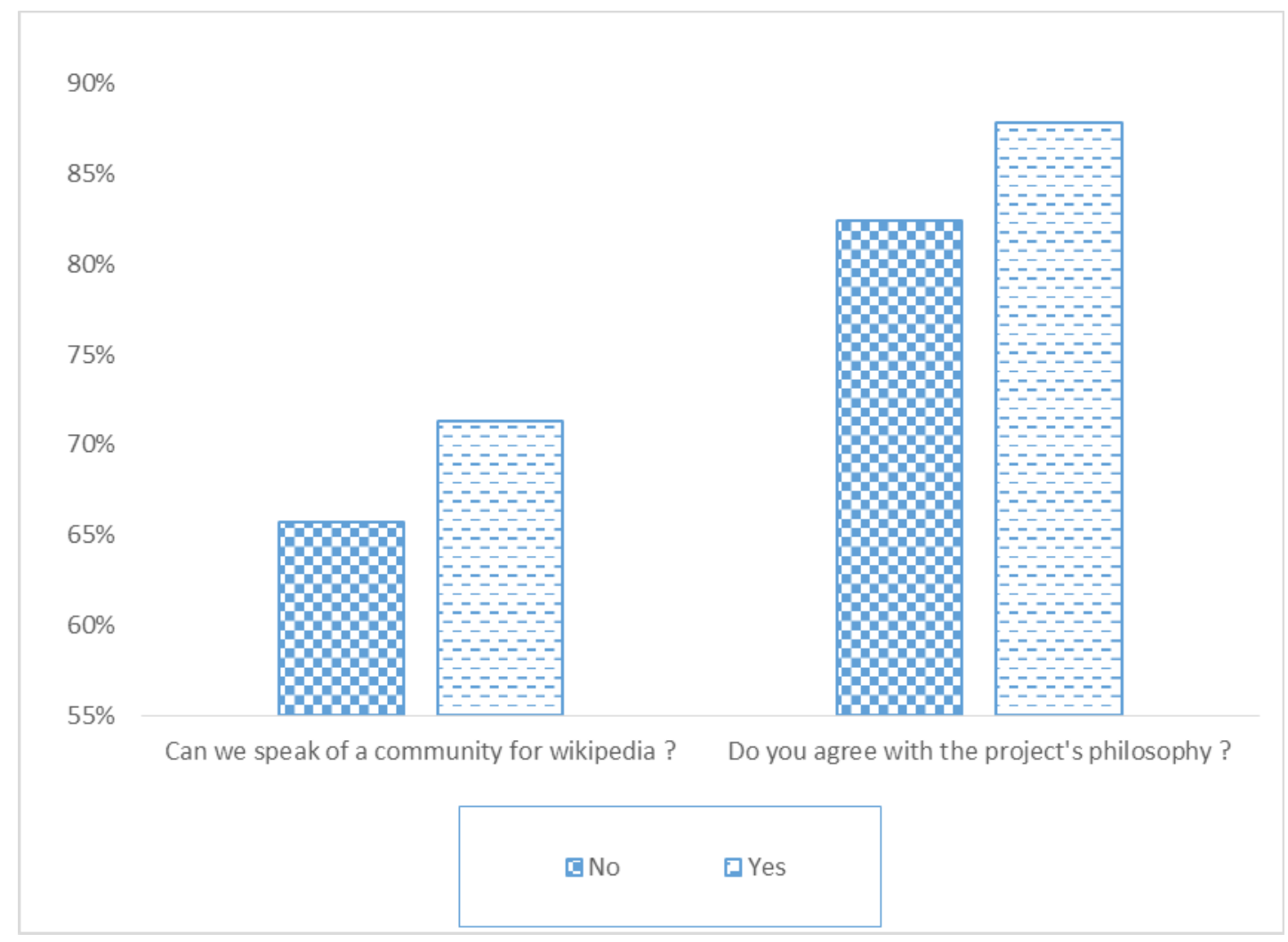

(in horizontal dashed line, those who chose the equal split in the DG, in chekerboard pattern those who didn't) 
We can confidently claim that the project has developed mechanisms, among which identity feelings, that trigger cooperative behaviors, elicited in the 50/50 split (Figure 2 showed that those who feel that there is a Wikipedia community, or who agree with the project's philosophy choose the equal split more than those who don't). The socio-demographic variables seem to indicate that these behaviors probably result from broader homo-reciprocans behaviors, since those who usually cooperate more (women and young people) are also those who cooperate more in our context. The project does not force cooperation, but develops mechanisms which select / enforce such pre-existing tendency. However, and to use a metaphor from physics, we do not know what is the potential, what triggers the force inducing the people to adopt a local norm: the balance between 'identity' and 'social norm reminders is out of the reach of this study.

Showing strong evidences that the prosocial attitude is endogenously determined inside the community remains challenging. We agree that the method of instrumental variable used in this article doesn't prove the existence of this causality, but we would like to defend the idea that under the assumption that our instrument is valid, this a first piece of evidence that prosocial motivations, which support the norm, can result from involvement in the community. Additional researches is needed to disentangle what is due to pre-existing inclination toward pro-social attitude and what is fostered by the institutional framework.

Another limitation of our study is our data collection methodology. Before playing the DG, people had to complete a survey about their usage of and attachment to Wikipedia. The flipside of this methodology is that we were unable to evaluate how answers were influenced by the survey. The protocol itself created a bias: people had already given 20 minutes of their time to complete the questionnaire, and this alone demonstrates a prosocial attitude. Our sample is thus definitely unrepresentative of the entire Wikipedia community. This bias does not alter the value of our work, however, since the aim was to look at the determinants of active Wikipedia users (contributors) and other (pro-social) users. The DG calibrated the degree of sociability of this pro-social population and tested whether it was linked to their commitment to Wikipedia. The fact that most people (who were probably less committed) did not answer the questionnaire is thus irrelevant. The low financial incentives are probably also responsible for the low number of respondents who chose to give nothing in the DG. When a traditional DG is played in a laboratory setting, selfish behavior is the main mode among the answers and we are unable to estimate how our protocol prevented users from making this choice.

We can also question the use of the DG to reveal a social norm, especially in the context of an open online community free of financial incentives to contribute. Advantages of using the DG are its simplicity and the fact that this game appears as a standard in the literature, and thus helps to understand its determinants and make comparisons. In the specific context of Wikipedia, we can consider that the choice to sacrifice financial resources in the DG reveals a norm which is in line with thinking that contributors are not paid (or sacrifice resources) to write articles, Which can be confirmed by the role played by the variable Edit_Paid in Table 5. However, as prosocial behavior takes various forms in an open online community (writing articles, fixing spelling mistakes, giving attention by reading or simply promoting the platform) original or modified versions of traditional experiments probably have to be considered. Asking the "dictator" to give his or her endowment to a charity, as done by Carpenter and Myers (2010), may be another means to elicit the norm in this context, as much as designing experiments where users share non-financial resources like time, attention or contribution, such as asking them if they agree to spend additional time to do a task at the end of a questionnaire. The online environment undoubtedly creates a fertile experimental field to propose a new methodology to reveal social norms and prosocial motivations and should be put in the research agenda.

\section{Conclusion}

In this paper we showed that a social norm has emerged from the patronage of a collective online project, Wikipedia. This norm is revealed by the choice of the equal split in the dictator 
game.

We found that there is no differences between contributors and simple (but committed) users of the online encyclopedia in their behavior in the DG. Our results show that usage, involvement and time spent on Wikipedia, are responsible for the choice of this social norm of sharing. This result challenges the existing literature which suggests that prosocial motivations are correlated with voluntary contributions. It may be that these prosocial motivations are shared among all the participants in a 'community', and are not unique to those who are involved in the production of knowledge. Results based on the method of instrumental variables gives an indication that the adherence to the social norm of sharing may be endogenously determined in the open online community. This last result supports the fact that massive open online communities, via their socio-technical and institutional framework (Hess and Ostrom, 2006), may trigger implicit socialization within the whole community, and not only among contributors.

Although the pro-social norm has been widely studied in the literature, it remains difficult to clearly understand what is behind the adhesion to this norm. Especially in the case of Wikipedia, but also in any other massive online contributive community, further research is required to confirm the existence of this norm and its role in the provision of a shared resource. Finally, the consequences of the fact that both contributors and non-contributors share common social motivations merits further investigation, as well as the experimental tools to do so.

\section{Acknowledgements}

This work has been funded by a grant from Agence Nationale de la Recherche (French NSF). The authors thank the Wikimédia Foundation France, the administrators of the French Wikipedia, and the people who answered to the questionnaire. 


\section{References}

Akerlof, G.A., Kranton, R.E., 2000. Economics and identity. Quarterly journal of Economics 715-753.

Algan, Y., Benkler, Y., Morell, M.F., Hergueux, J., 2013. Cooperation in a Peer Production Economy Experimental Evidence from Wikipedia, in: Workshop on Information Systems and Economics. Milan, Italy, pp. 1-31.

Andreoni, J., Bernheim, B.D., 2009. Social image and the 50-50 norm: A theoretical and experimental analysis of audience effects. Econometrica 77, 1607-1636.

Bardsley, N., 2008. Dictator game giving: altruism or artefact? Experimental Economics 11, 122-133.

Battigalli, P., Dufwenberg, M., 2007. Guilt in games. The American Economic Review 97, $170-176$.

Bicchieri, C., 2002. Covenants without swords. Group identity, norms, and communication in social dilemmas. Rationality and Society 14, 192-228.

Bound, J., Jaeger, D.A., Baker, R.M., 1995. Problems with instrumental variables estimation when the correlation between the instruments and the endogenous explanatory variable is weak. Journal of the American statistical association 90, 443-450.

Butler, B., Sproull, L., Kiesler, S., Kraut, R., 2007. Community effort in online groups: Who does the work and why?, in: Weisband, S. (Ed.), Leadership at a Distance: Research in Technologically Supported Work. Lawrence Erlbaum, Mahwah, NJ.

Carpenter, J., Myers, C.K., 2010. Why volunteer? Evidence on the role of altruism, image, and incentives. Journal of Public Economics 94, 911-920.

Commons, J.R., 1931. Institutional economics. The American economic review 648-657.

Dejean, S., Jullien, N., 2015. Big From the Beginning. Assessing Online Contributors’ Behavior by Their First Contribution. Research Policy 44, 1226-1239.

Eckel, C., Grossman, P.J., Johnson, C.A., de Oliveira, A.C., Rojas, C., Wilson, R., 2011. Social norms of sharing in high school: teen giving in the dictator game. Journal of Economic Behavior \& Organization 80, 603-612.

Eckel, C.C., Grossman, P.J., 1996. Altruism in anonymous dictator games. Games and economic behavior 16, 181-191.

Elster, J., 1989. The Cement of Society. Cambridge University Press.

Engel, C., 2011. Dictator games: a meta study. Experimental Economics 14, 583-610.

Ensminger, J., 2004. Market integration and fairness: evidence from ultimatum, dictator, and public goods experiments in East Africa. Foundations of human sociality: economic experiments and ethnographic evidence from 15 small-scale societies 356-381.

Gächter, S., 2014. Human Prosocial Motivation and the Maintenance of Social Order. The Oxford Handbook of Behavioral Economics and the Law 28.

Gintis, H., Bowles, S., Boyd, R., Fehr, E., 2003. Explaining altruistic behavior in humans. Evolution and Human Behavior 24, 153-172.

Greenstein, S., Gu, Y., Zhu, F., 2016. Ideological Segregation among Online Collaborators: Evidence from Wikipedians (Working Paper No. 22744). National Bureau of Economic Research. doi:10.3386/w22744

Henrich, J., Ensminger, J., McElreath, R., Barr, A., Barrett, C., Bolyanatz, A., Cardenas, J.C., Gurven, M., Gwako, E., Henrich, N., others, 2010. Markets, religion, community size, and the evolution of fairness and punishment. science 327, 1480-1484.

Hess, C., Ostrom, E., 2006. Introduction: An Overview of the Knowledge Commons, in: IcitepHessOstrom06 (Ed.), Understanding Knowledge as a Commons. From Theory to Practice. pp. 3-26.

Hoffman, E., McCabe, K., Smith, V.L., 1996. Social distance and other-regarding behavior in dictator games. The American Economic Review 653-660.

Krupka, E.L., Weber, R.A., 2013. Identifying social norms using coordination games: Why does dictator game sharing vary? Journal of the European Economic Association 11, 495-524.

List, J.A., 2007. On the interpretation of giving in dictator games. Journal of Political Economy 115, 482-493. 
Rosch, E., 1975. Cognitive reference points. Cognitive psychology 7, 532-547.

Safner, R., 2016. Institutional entrepreneurship, Wikipedia, and the opportunity of the commons. Journal of Institutional Economics 1-29.

Schelling, T.S., 1960. The Strategy of Conflict, trad. fr.2e ed. 1980: Stratégie du Conflit, PUF Paris 1986. ed. Harvard University Press.

Seabright, P., 2012. The company of strangers: A natural history of economic life. Princeton University Press.

Sugden, R., 1995. The coexistence of conventions. Journal of Economic Behavior and Organization 28, 241-256.

Tisserand, J., Cochard, F., Le Gallo, J., 2015. Altruistic or strategic considerations: A metaanalysis on the ultimatum and dictator games, in: The Annual Meeting of the French Economic Association, Rennes, France.

Young, H.P., 2015. The Evolution of Social Norms. Annual Review of Economics 7, 359-387.

Young, H.P., 1998. Social norms and economic welfare. European Economic Review 821830.

Zhang, X., Zhu, F., 2011. Group Size and Incentives to Contribute: A Natural Experiment at Chinese Wikipedia. The American Economic Review 101, 1601-1615.

Zhou, T., 2011. Understanding online community user participation: a social influence perspective. Internet Research 21, 67-81. 
Table 1 : Descriptive statistics and description of the variables

\begin{tabular}{|c|c|c|c|c|c|}
\hline VARIABLES & Description & Mean & Sd. & Min & Max \\
\hline Contrib1 & 1 if the respondent has never contributed to Wikipedia & 0.650 & 0.477 & 0 & 1 \\
\hline Contrib2 & $\begin{array}{l}1 \text { if the respondent is a regular contributor to Wikipedia, } 0 \\
\text { otherwise }\end{array}$ & 0.296 & 0.456 & 0 & 1 \\
\hline Contrib3 & $\begin{array}{l}1 \text { if the respondent has occasionally contributed to } \\
\text { Wikipedia, } 0 \text { otherwise }\end{array}$ & 0.046 & 0.209 & 0 & 1 \\
\hline WikiTime & $\begin{array}{l}\text { Number of years since the discovery of Wikipedia (in six } \\
\text { classes increasing with seniority }\end{array}$ & 4.039 & 1.010 & 1 & 6 \\
\hline French & 1 if living in France, 0 otherwise & 0.774 & 0.418 & 0 & 1 \\
\hline Age16 & 1 if aged under 16, 0 otherwise & 0.118 & 0.323 & 0 & 1 \\
\hline Age20 & 1 if aged $16-20,0$ otherwise & 0.210 & 0.407 & 0 & 1 \\
\hline Age30 & 1 if aged $21-30,0$ otherwise & 0.238 & 0.426 & 0 & 1 \\
\hline Age50 & 1 if aged $31-40,0$ otherwise & 0.206 & 0.405 & 0 & 1 \\
\hline Age+ + & 1 if older than 50, 0 otherwise & 0.227 & 0.419 & 0 & 1 \\
\hline Education1 & 1 if high school, 0 otherwise & 0.241 & 0.428 & 0 & 1 \\
\hline Education 2 & 1 if between high school and undergraduate, 0 otherwis & 0.133 & 0.339 & 0 & 1 \\
\hline Education 3 & 1 if undergraduate, 0 otherwise & 0.196 & 0.397 & 0 & 1 \\
\hline Education 4 & 1 if a graduate or with further qualifications, 0 otherwise & 0.171 & 0.376 & 0 & 1 \\
\hline Education 5 & 1 if holding a professional diploma, 0 otherwise & 0.246 & 0.431 & 0 & 1 \\
\hline Income1 & 1 if has a comfortable level of income, 0 otherwise & 0.535 & 0.499 & 0 & 1 \\
\hline Income2 & 1 if considers that income meets needs, 0 otherwise & 0.326 & 0.469 & 0 & 1 \\
\hline Income3 & 1 if considers that income makes life difficult, 0 otherwise & 0.126 & 0.332 & 0 & 1 \\
\hline Employed & 1 if employed, 0 otherwise & 0.325 & 0.468 & 0 & 1 \\
\hline Unemployed & 1 if unemployed, 0 otherwise & 0.096 & 0.296 & 0 & 1 \\
\hline Retired & 1 if retired, 0 otherwise & 0.117 & 0.321 & 0 & 1 \\
\hline Student & 1 if pursuing studies, 0 otherwise & 0.456 & 0.498 & 0 & 1 \\
\hline $50 / 50$ & 1 if the respondent gave half in the DG, 0 otherwise & 0.667 & 0.471 & 0 & 1 \\
\hline $0 / 10$ & 1 if the respondent gave nothing in the DG, 0 otherwise & 0.050 & 0.219 & 0 & 1 \\
\hline $10 / 0$ & 1 if the respondent gave all in the DG, 0 otherwise & 0.117 & 0.322 & 0 & 1 \\
\hline WikiUse_Pro & $\begin{array}{l}\text { Score ranging from } 3 \text { to } 12.3 \text { represents never using } \\
\text { Wikipedia and } 12 \text { represents using it intensively for } \\
\text { professional purposes }\end{array}$ & 9.312 & 2.239 & 3 & 12 \\
\hline WikiUse & $\begin{array}{l}\text { Score ranging from } 3 \text { to } 12.3 \text { represents never using } \\
\text { Wikipedia and } 12 \text { represents using it intensively for } \\
\text { personal purposes }\end{array}$ & 9.917 & 2.162 & 3 & 12 \\
\hline Deep_know1 & $\begin{array}{l}1 \text { if the respondent never used Wikipedia to discover new } \\
\text { thing or deep his knowledge , } 0 \text { otherwise }\end{array}$ & 0.182 & 0.386 & 0 & 1 \\
\hline Deep_know 2 & $\begin{array}{l}1 \text { if the respondent used Wikipedia to discover new thing or } \\
\text { deep his knowledge rarely or sometimes, } 0 \text { otherwise }\end{array}$ & 0.341 & 0.474 & 0 & 1 \\
\hline Deep_know 3 & $\begin{array}{l}1 \text { if the respondent used Wikipedia to discover new thing or } \\
\text { deep his knowledge often, } 0 \text { otherwise }\end{array}$ & 0.362 & 0.480 & 0 & 1 \\
\hline Look_def1 & $\begin{array}{l}1 \text { if the respondent never used Wikipedia tolook for a } \\
\text { definiton information, } 0 \text { otherwise }\end{array}$ & 0.142 & 0.349 & 0 & 1 \\
\hline Look_def 2 & $\begin{array}{l}1 \text { if the respondent used Wikipedia to look for a definiton } \\
\text { rarely or sometimes, } 0 \text { otherwise }\end{array}$ & 0.275 & 0.447 & 0 & 1 \\
\hline Look_def 3 & $\begin{array}{l}1 \text { if the respondent used Wikipedia to look for a definiton } \\
\text { often, } 0 \text { otherwise }\end{array}$ & 0.582 & 0.493 & 0 & 1 \\
\hline Check_info1 & $\begin{array}{l}1 \text { if the respondent never used Wikipedia to check } \\
\text { information, } 0 \text { otherwise }\end{array}$ & 0.146 & 0.353 & 0 & 1 \\
\hline Check_info 2 & $\begin{array}{l}1 \text { if the respondent used Wikipedia to check information } \\
\text { rarely or sometimes, } 0 \text { otherwise }\end{array}$ & 0.306 & 0.461 & 0 & 1 \\
\hline Check_info 3 & $\begin{array}{l}1 \text { if the respondent used Wikipedia to check information } \\
\text { often, } 0 \text { otherwise }\end{array}$ & 0.549 & 0.498 & 0 & 1 \\
\hline Edit_Paid & $\begin{array}{l}1 \text { if the respondent thought that some article writers were } \\
\text { paid to do so and } 0 \text { otherwise }\end{array}$ & 0.304 & 0.460 & 0 & 1 \\
\hline
\end{tabular}


Wikipref3 1 if the disappearance of Wikipedia would be a disaster, 0

$\begin{array}{llll}0.344 & 0.475 & 0 & 1\end{array}$

Wikipref2 1 if the disappearance of Wikipedia would be a major loss,

$\begin{array}{llll}0.546 & 0.498 & 0 & 1\end{array}$ 0 otherwise

Wikipref1 1 if the disappearance of Wikipedia would be somewhat

$\begin{array}{llll}0.110 & 0.313 & 0 & 1\end{array}$ harmful, 0 otherwise

Smart one if the respondent consults Wikipédia using a smartphone, 0 otherwise 
Table 2 : Estimates of $50 / 50$ choices in the DG

\begin{tabular}{|c|c|c|c|c|c|c|c|}
\hline VARIABLES & $\begin{array}{c}(1) \\
50 / 50 \\
\end{array}$ & $\begin{array}{c}(2) \\
50 / 50 \\
\end{array}$ & $\begin{array}{c}(3) \\
50 / 50 \\
\end{array}$ & $\begin{array}{c}(4) \\
50 / 50 \\
\end{array}$ & $\begin{array}{c}(5) \\
50 / 50 \\
\end{array}$ & $\begin{array}{c}(6) \\
50 / 50 \\
\end{array}$ & $\begin{array}{c}(7) \\
50 / 50 \\
\end{array}$ \\
\hline Check_info3 & $\begin{array}{c}0.120 * * * \\
(0.036)\end{array}$ & & & & & & \\
\hline Check_info2 & $\begin{array}{c}0.166 * * * \\
(0.034)\end{array}$ & & & & & & \\
\hline Check_info1 & Ref. & & & & & & \\
\hline Look_def3 & & $\begin{array}{c}0.109 * * * \\
(0.037)\end{array}$ & & & & & \\
\hline Look_def2 & & $\begin{array}{c}0.111^{* * * *} \\
(0.034)\end{array}$ & & & & & \\
\hline Look_def1 & & Ref. & & & & & \\
\hline Dep_know3 & & & $\begin{array}{c}0.098 * * * \\
(0.028)\end{array}$ & & & & \\
\hline Dep_know2 & & & $\begin{array}{c}0.100^{* * *} \\
(0.028)\end{array}$ & & & & \\
\hline Dep_know1 & & & Ref. & & & & \\
\hline Wikiuse & & & & $\begin{array}{c}0.029 * * * \\
(0.006)\end{array}$ & & & \\
\hline Wikipref3 & & & & & $\begin{array}{c}0.256^{* * *} \\
(0.038)\end{array}$ & & \\
\hline Wikipref2 & & & & & $\begin{array}{c}0.229 * * * \\
(0.036)\end{array}$ & & \\
\hline Wikipref1 & & & & & Ref. & & \\
\hline WikiTime & & & & & & $\begin{array}{l}0.021^{*} \\
(0.012)\end{array}$ & \\
\hline Contrib3 & & & & & & & $\begin{array}{c}0.010 \\
(0.025)\end{array}$ \\
\hline Contrib2 & & & & & & & $\begin{array}{c}-0.009 \\
(0.054)\end{array}$ \\
\hline Contrib1 & & & & & & & Ref. \\
\hline Constant & $\begin{array}{c}0.377 * * * \\
(0.059)\end{array}$ & $\begin{array}{c}0.414 * * * \\
(0.059)\end{array}$ & $\begin{array}{c}0.442^{* * *} \\
(0.055)\end{array}$ & $\begin{array}{c}0.221^{* * *} \\
(0.076)\end{array}$ & $\begin{array}{c}0.310^{* * *} \\
(0.060)\end{array}$ & $\begin{array}{c}0.424 * * * \\
(0.073)\end{array}$ & $\begin{array}{c}0.511 * * * \\
(0.052)\end{array}$ \\
\hline Socio-demo & YES & YES & YES & YES & YES & YES & YES \\
\hline Observations & 13,672 & 13,672 & 13,672 & 13,672 & 13,672 & 13,672 & 13,672 \\
\hline Log Likelihood & -8634 & -8640 & -8638 & -8633 & -8622 & -8645 & -8646 \\
\hline
\end{tabular}


Table 3 : Estimates of 50/50, 0/10 and 10/0 choices in the DG

\begin{tabular}{|c|c|c|c|c|c|c|}
\hline \multirow[b]{2}{*}{ VARIABLES } & \multicolumn{2}{|c|}{ 50/50 (Equal split) } & \multicolumn{2}{|c|}{ 0/10(Selfish) } & \multicolumn{2}{|c|}{ 10/0 (altruistic) } \\
\hline & $(1)$ & (1b) & (2) & (2b) & (3) & (3b) \\
\hline WikiUse & $\begin{array}{c}0.020 * * * \\
(0.006)\end{array}$ & & $\begin{array}{c}-0.015^{*} \\
(0.009)\end{array}$ & & $\begin{array}{c}-0.016^{* *} \\
(0.008)\end{array}$ & \\
\hline WikiPref3 & $\begin{array}{c}0.215^{* * * *} \\
(0.040)\end{array}$ & $\begin{array}{c}0.220 * * * \\
(0.040)\end{array}$ & $\begin{array}{c}-0.207 * * * \\
(0.061)\end{array}$ & $\begin{array}{c}-0.238 * * * \\
(0.061)\end{array}$ & $\begin{array}{c}-0.117^{* *} \\
(0.050)\end{array}$ & $\begin{array}{c}-0.123^{* *} \\
(0.050)\end{array}$ \\
\hline WikiPref2 & $\begin{array}{c}0.203 * * * \\
(0.037)\end{array}$ & $\begin{array}{c}0.204 * * * \\
(0.037)\end{array}$ & $\begin{array}{c}-0.234^{* * *} \\
(0.056)\end{array}$ & $\begin{array}{c}-0.248 * * * \\
(0.056)\end{array}$ & $\begin{array}{c}-0.180^{* * *} \\
(0.046)\end{array}$ & $\begin{array}{c}-0.184 * * * \\
(0.046)\end{array}$ \\
\hline WikiPref1 & Ref. & Ref. & Ref. & Ref. & Ref. & Ref. \\
\hline WikiTime & $\begin{array}{c}0.009 \\
(0.012)\end{array}$ & $\begin{array}{c}0.009 \\
(0.012)\end{array}$ & $\begin{array}{c}0.002 \\
(0.021)\end{array}$ & $\begin{array}{c}-0.002 \\
(0.021)\end{array}$ & $\begin{array}{c}-0.014 \\
(0.015)\end{array}$ & $\begin{array}{c}-0.014 \\
(0.015)\end{array}$ \\
\hline Contrib3 & $\begin{array}{c}-0.004 \\
(0.026)\end{array}$ & $\begin{array}{c}-0.004 \\
(0.026)\end{array}$ & $\begin{array}{c}0.086^{* *} \\
(0.041)\end{array}$ & $\begin{array}{c}0.083^{* *} \\
(0.041)\end{array}$ & $\begin{array}{l}-0.056^{*} \\
(0.033)\end{array}$ & $\begin{array}{l}-0.056^{*} \\
(0.033)\end{array}$ \\
\hline Contrib2 & $\begin{array}{l}-0.033 \\
(0.055)\end{array}$ & $\begin{array}{c}-0.034 \\
(0.055)\end{array}$ & $\begin{array}{c}0.189 * * \\
(0.084)\end{array}$ & $\begin{array}{c}0.182^{* *} \\
(0.084)\end{array}$ & $\begin{array}{l}-0.021 \\
(0.068)\end{array}$ & $\begin{array}{l}-0.019 \\
(0.068)\end{array}$ \\
\hline Contrib1 & Ref. & Ref. & Ref. & Ref. & Ref. & Ref. \\
\hline Check_info3 & & $\begin{array}{c}0.073^{*} \\
(0.039)\end{array}$ & & $\begin{array}{c}-0.066 \\
(0.061)\end{array}$ & & $\begin{array}{c}-0.069 \\
(0.051)\end{array}$ \\
\hline Check_info2 & & $\begin{array}{c}0.119 * * * \\
(0.041)\end{array}$ & & $\begin{array}{c}0.033 \\
(0.064)\end{array}$ & & $\begin{array}{l}-0.097^{*} \\
(0.053)\end{array}$ \\
\hline Check_info1 & & Ref. & & Ref. & & Ref. \\
\hline Look_def3 & & $\begin{array}{c}0.049 \\
(0.040)\end{array}$ & & $\begin{array}{l}-0.085 \\
(0.063)\end{array}$ & & $\begin{array}{c}0.040 \\
(0.052)\end{array}$ \\
\hline Look_def2 & & $\begin{array}{c}-0.001 \\
(0.041)\end{array}$ & & $\begin{array}{c}-0.072 \\
(0.064)\end{array}$ & & $\begin{array}{c}0.019 \\
(0.054)\end{array}$ \\
\hline Look_def1 & & Ref. & & Ref. & & Ref. \\
\hline Dep_know3 & & $\begin{array}{l}0.056^{*} \\
(0.030)\end{array}$ & & $\begin{array}{l}-0.047 \\
(0.048)\end{array}$ & & $\begin{array}{c}-0.065^{*} \\
(0.039)\end{array}$ \\
\hline Dep_know2 & & $\begin{array}{c}0.038 \\
(0.032)\end{array}$ & & $\begin{array}{c}-0.012 \\
(0.050)\end{array}$ & & $\begin{array}{l}-0.018 \\
(0.041)\end{array}$ \\
\hline Dep_know1 & & Ref. & & Ref. & & Ref. \\
\hline Constant & $\begin{array}{c}0.097 \\
(0.090)\end{array}$ & $\begin{array}{l}0.160^{*} \\
(0.082)\end{array}$ & $\begin{array}{c}-1.289 * * * \\
(0.147)\end{array}$ & $\begin{array}{c}-1.332 * * * \\
(0.133)\end{array}$ & $\begin{array}{c}-0.843^{* * *} \\
(0.114)\end{array}$ & $\begin{array}{c}-0.917 * * * \\
(0.103)\end{array}$ \\
\hline Socio-demo & YES & YES & YES & YES & YES & YES \\
\hline Observations & 13,672 & 13,672 & 13,672 & 13,672 & 13,672 & 13,672 \\
\hline Log Likelihood & -8616 & -8612 & -2688 & -2684 & -4799 & -4797 \\
\hline
\end{tabular}


Table 4 : Socio-demographic variables of column (1), (2) and (3) of table 3

\begin{tabular}{|c|c|c|c|}
\hline VARIABLES & $\begin{array}{c}50 / 50 \text { (equal split) } \\
\text { (1) }\end{array}$ & $\begin{array}{c}10 / 0 \text { (selfish) } \\
(2)\end{array}$ & $\begin{array}{c}0 / 10 \text { (altruistic) } \\
\text { (3) }\end{array}$ \\
\hline Gender & $\begin{array}{c}-0.167 * * * \\
(0.024)\end{array}$ & $\begin{array}{c}0.061 \\
(0.040)\end{array}$ & $\begin{array}{c}0.238 * * * \\
(0.032)\end{array}$ \\
\hline Age16 & $\begin{array}{l}-0.001 \\
(0.069)\end{array}$ & $\begin{array}{c}0.147 \\
(0.111)\end{array}$ & $\begin{array}{c}-0.305^{* * * *} \\
(0.091)\end{array}$ \\
\hline Age20 & $\begin{array}{l}0.099 * \\
(0.060)\end{array}$ & $\begin{array}{c}0.084 \\
(0.099)\end{array}$ & $\begin{array}{c}-0.366^{* * * *} \\
(0.077)\end{array}$ \\
\hline Age30 & $\begin{array}{c}0.125^{* * *} \\
(0.046)\end{array}$ & $\begin{array}{c}0.014 \\
(0.075)\end{array}$ & $\begin{array}{c}-0.235^{* * *} \\
(0.057)\end{array}$ \\
\hline Age50 & $\begin{array}{l}0.098 * * \\
(0.042)\end{array}$ & $\begin{array}{l}-0.073 \\
(0.071)\end{array}$ & $\begin{array}{c}-0.122^{* *} \\
(0.050)\end{array}$ \\
\hline Age+ & Ref. & Ref. & Ref. \\
\hline Income1 & $\begin{array}{l}-0.059 * \\
(0.036)\end{array}$ & $\begin{array}{l}-0.069 \\
(0.056)\end{array}$ & $\begin{array}{c}0.063 \\
(0.046)\end{array}$ \\
\hline Income1 & $\begin{array}{c}0.007 \\
(0.037)\end{array}$ & $\begin{array}{l}-0.098 * \\
(0.059)\end{array}$ & $\begin{array}{l}-0.030 \\
(0.047)\end{array}$ \\
\hline Income3 & Ref. & Ref. & Ref. \\
\hline Educ1 & $\begin{array}{c}0.011 \\
(0.041)\end{array}$ & $\begin{array}{l}-0.113^{*} \\
(0.066)\end{array}$ & $\begin{array}{c}0.108 * * \\
(0.053)\end{array}$ \\
\hline Educ2 & $\begin{array}{c}0.029 \\
(0.041)\end{array}$ & $\begin{array}{l}-0.117^{*} \\
(0.068)\end{array}$ & $\begin{array}{c}0.080 \\
(0.052)\end{array}$ \\
\hline Educ 3 & $\begin{array}{c}0.040 \\
(0.036)\end{array}$ & $\begin{array}{l}-0.185^{* * *} \\
(0.060)\end{array}$ & $\begin{array}{l}0.091 * * \\
(0.045)\end{array}$ \\
\hline Educ 4 & $\begin{array}{c}0.051 \\
(0.036)\end{array}$ & $\begin{array}{l}-0.257 * * * \\
(0.062)\end{array}$ & $\begin{array}{c}0.017 \\
(0.045)\end{array}$ \\
\hline Educ5 & Ref. & Ref. & Ref. \\
\hline Unemployed & $\begin{array}{l}-0.043 \\
(0.043)\end{array}$ & $\begin{array}{l}0.130^{*} \\
(0.070)\end{array}$ & $\begin{array}{l}-0.056 \\
(0.054)\end{array}$ \\
\hline Retired & $\begin{array}{l}-0.085^{*} \\
(0.047)\end{array}$ & $\begin{array}{c}0.083 \\
(0.080)\end{array}$ & $\begin{array}{l}0.121^{* *} \\
(0.055)\end{array}$ \\
\hline Student & $\begin{array}{l}-0.042 \\
(0.043)\end{array}$ & $\begin{array}{c}0.092 \\
(0.071)\end{array}$ & $\begin{array}{c}-0.129 * * \\
(0.056)\end{array}$ \\
\hline Employed & Ref. & Ref. & Ref. \\
\hline Constant & $\begin{array}{c}0.097 \\
(0.090)\end{array}$ & $\begin{array}{c}-1.289 * * * \\
(0.147)\end{array}$ & $\begin{array}{c}-0.843^{* * *} \\
(0.114)\end{array}$ \\
\hline Involvement variables & YES & YES & YES \\
\hline Observations & 13,672 & 13,672 & 13,672 \\
\hline Log Likelihood & -8616 & -2688 & -4799 \\
\hline
\end{tabular}


Table 5 : Estimates of equal split with additional control variables

\begin{tabular}{|c|c|c|c|c|}
\hline VARIABLES & $\begin{array}{c}50 / 50 \\
(1) \\
\end{array}$ & $\begin{array}{c}50 / 50 \\
(2) \\
\end{array}$ & $\begin{array}{c}50 / 50 \\
(3)\end{array}$ & $\begin{array}{c}50 / 50 \\
(4)\end{array}$ \\
\hline WikiUse_Pro & $\begin{array}{l}-0.011^{*} \\
(0.006)\end{array}$ & & & $\begin{array}{l}-0.009 \\
(0.006)\end{array}$ \\
\hline Edit_Paid & & $\begin{array}{c}-0.087 * * * \\
(0.025)\end{array}$ & & $\begin{array}{c}-0.084 * * * \\
(0.025)\end{array}$ \\
\hline French & & & $\begin{array}{c}0.129 * * * \\
(0.027)\end{array}$ & $\begin{array}{c}0.124 * * * \\
(0.027)\end{array}$ \\
\hline WikiUse & $\begin{array}{c}0.025 * * * \\
(0.006)\end{array}$ & $\begin{array}{c}0.019 * * * \\
(0.006)\end{array}$ & $\begin{array}{c}0.020 * * * \\
(0.006)\end{array}$ & $\begin{array}{c}0.023 * * * \\
(0.006)\end{array}$ \\
\hline WikiPref3 & $\begin{array}{c}0.222 * * * \\
(0.040)\end{array}$ & $\begin{array}{c}0.212 * * * \\
(0.040)\end{array}$ & $\begin{array}{c}0.218 * * * \\
(0.040)\end{array}$ & $\begin{array}{c}0.220 * * * \\
(0.041)\end{array}$ \\
\hline WikiPref2 & $\begin{array}{c}0.206 * * * \\
(0.037)\end{array}$ & $\begin{array}{c}0.201 * * * \\
(0.037)\end{array}$ & $\begin{array}{c}0.202 * * * \\
(0.037)\end{array}$ & $\begin{array}{c}0.204^{* * *} \\
(0.037)\end{array}$ \\
\hline WikiPref1 & Ref. & Ref. & Ref. & Ref. \\
\hline WikiTime & $\begin{array}{c}0.010 \\
(0.012)\end{array}$ & $\begin{array}{c}0.010 \\
(0.012)\end{array}$ & $\begin{array}{c}0.008 \\
(0.012)\end{array}$ & $\begin{array}{c}0.010 \\
(0.012)\end{array}$ \\
\hline Contrib3 & $\begin{array}{c}-0.003 \\
(0.026)\end{array}$ & $\begin{array}{c}-0.003 \\
(0.026)\end{array}$ & $\begin{array}{l}-0.004 \\
(0.026)\end{array}$ & $\begin{array}{l}-0.004 \\
(0.026)\end{array}$ \\
\hline Contrib2 & $\begin{array}{l}-0.035 \\
(0.055)\end{array}$ & $\begin{array}{c}-0.028 \\
(0.055)\end{array}$ & $\begin{array}{l}-0.038 \\
(0.055)\end{array}$ & $\begin{array}{l}-0.035 \\
(0.055)\end{array}$ \\
\hline Contrib1 & Ref. & Ref. & Ref. & Ref. \\
\hline Constant & $\begin{array}{l}0.156^{*} \\
(0.094)\end{array}$ & $\begin{array}{c}0.120 \\
(0.091)\end{array}$ & $\begin{array}{c}0.006 \\
(0.092)\end{array}$ & $\begin{array}{c}0.085 \\
(0.096)\end{array}$ \\
\hline Socio-demo & YES & YES & YES & YES \\
\hline Observations & 13,539 & 13,672 & 13,672 & 13,539 \\
\hline Log Likelihood & -8524 & -8609 & -8604 & -8508 \\
\hline
\end{tabular}


Table 6 : Estimates of equal split with the instrumental variable

\begin{tabular}{|c|c|c|c|c|c|c|c|c|}
\hline \multirow[b]{2}{*}{ VARIABLES } & \multicolumn{2}{|c|}{ IV } & \multicolumn{2}{|r|}{ IV } & \multicolumn{2}{|c|}{ IV } & \multicolumn{2}{|c|}{ IV } \\
\hline & $50 / 50$ & WikiUse & $50 / 50$ & Check_info3 & $50 / 50$ & WikiPref3 & $50 / 50$ & WikiTime \\
\hline WikiUse & $\begin{array}{c}0.061^{* * *} \\
(0.018)\end{array}$ & & & & & & & \\
\hline SmartWiki & & $\begin{array}{c}0.690 * * * \\
(0.038)\end{array}$ & & $\begin{array}{c}0.432 * * * \\
(0.025)\end{array}$ & & $\begin{array}{c}0.244 * * * \\
(0.034)\end{array}$ & & $\begin{array}{c}0.080 * * * \\
(0.017)\end{array}$ \\
\hline Check_info3 & & & $\begin{array}{l}0.149 * \\
(0.078)\end{array}$ & & & & & \\
\hline WikiPref3 & & & & & $\begin{array}{c}0.342 * * * \\
(0.126)\end{array}$ & & & \\
\hline Wikitime & & & & & & & $\begin{array}{c}0.096 * * * \\
(0.034)\end{array}$ & \\
\hline Constant & $\begin{array}{c}-0.111 \\
(0.195)\end{array}$ & $\begin{array}{c}10.006^{* * *} \\
(0.083)\end{array}$ & $\begin{array}{c}0.417 * * * \\
(0.072)\end{array}$ & $\begin{array}{c}0.238 * * * \\
(0.054)\end{array}$ & $\begin{array}{l}0.219 * \\
(0.121)\end{array}$ & $\begin{array}{c}1.055^{* * *} \\
(0.070)\end{array}$ & $\begin{array}{c}0.101 \\
(0.154)\end{array}$ & $\begin{array}{c}4.311^{* * *} \\
(0.038)\end{array}$ \\
\hline Socio-demo & YES & YES & YES & YES & YES & YES & YES & YES \\
\hline Observations & 13,672 & 13,672 & 13,672 & 13,672 & 13,672 & 13,672 & 13,672 & 13,672 \\
\hline $\begin{array}{l}\text { Log } \\
\text { Likelihood }\end{array}$ & -35355 & -35355 & -16879 & -16879 & -12924 & -12924 & -25422 & -25422 \\
\hline
\end{tabular}

